\title{
Effectiveness and Safety of MLC601 in the Treatment of Mild to Moderate Alzheimer's Disease: A Multicenter, Randomized Controlled Trial
}

\author{
Hossein Pakdaman $^{a}$ Ali Amini Harandi ${ }^{a}$ Hamidreza Hatamian ${ }^{c}$ \\ Mojgan Tabatabae ${ }^{b}$ Hosein Delavar Kasmaei ${ }^{a} \quad$ Amirhossein Ghassemi $^{d}$ \\ Koroush Gharagozlia Farzad Ashrafi ${ }^{a}$ Pardis Emami Naeini ${ }^{\mathrm{a}}$ \\ Mehrnaz Tavakolian ${ }^{a}$ Darush Shahin ${ }^{a}$

\begin{abstract}
a Department of Neurology, Shahid Beheshti University of Medical Sciences, and
bSocial Security, Tehran, 'Department of Neurology, Rasht University of Medical Sciences, Rasht, d Social Security, Kerman, and e School of Medicine, Isfahan University of Medical
\end{abstract} \\ Sciences, Isfahan, Iran
}

\author{
Key Words \\ Cholinesterase inhibitor · Alzheimer's disease - Donepezil · Rivastigmine · Galantamine · \\ MLC601 · Safety $\cdot$ Efficacy
}

\begin{abstract}
Background: MLC601 is a possible modulator of amyloid precursor protein processing, and in a clinical trial study MLC601 showed some effectiveness in cognitive function in Alzheimer's disease (AD) patients. We aimed to evaluate the effectiveness and safety of MLC601 in the treatment of mild to moderate AD as compared to 3 approved cholinesterase inhibitors (ChEIs) including donepezil, rivastigmine and galantamine. Methods: In a multicenter, nonblinded, randomized controlled trial, 264 volunteers with $A D$ were randomly divided into 4 groups of 66; groups 1, 2, 3 and 4 received donepezil, rivastigmine, MLC601 and galantamine, respectively. Subjects underwent a clinical diagnostic interview and a cognitive/functional battery including the Mini-Mental State Examination (MMSE) and Alzheimer's Disease Assessment Scale - Cognitive subscale (ADAS-Cog). Patients were visited every 4 months, and the score of cognition was recorded by the neurologists. Results: There were no significant differences in age, sex, marital status and baseline score of cognition among the 4 groups. In total, 39 patients (14.7\%) left the study. Trend of cognition changes based on the modifications over the time for MMSE and ADAS-cog scores did not differ significantly among groups $(p=0.92$ for MMSE and $p=0.87$ for ADAS-Cog). Conclusion: MLC601 showed a promising safety profile and also efficacy compared to 3 FDA-approved ChEIs.


Pakdaman et al.: Effectiveness and Safety of MLC601 in the Treatment of Mild to Moderate Alzheimer's Disease: A Multicenter, Randomized Controlled Trial

\section{Introduction}

Alzheimer's disease (AD) is a progressive neurodegenerative disease characterized by cognitive deterioration together with behavioral disturbances and declining activities of daily living [1]. It is the leading cause of dementia, accounting for nearly $70 \%$ of dementia cases worldwide [2]. In the recent decade, the prevalence of dementia increased as the proportion of the elderly population expanded. The number of subjects with dementia has been doubling every 20 years and will reach 81.1 million by 2040 [3]. Although significant progress has been made in both understanding some of the mechanisms of AD pathology and developing therapeutic agents, these efforts have had no impact on decreasing disease prevalence and have had limited effects on improving the clinical course of AD [4].

Since 1993, five drugs have been marketed for the treatment of AD. Its current treatment includes cholinesterase inhibitors (ChEIs) [5-7], and N-methyl-D-aspartate receptor blockers [8]. In spite of enormous research efforts, these treatments are sometimes regarded as having only 'symptomatic' rather than 'disease-modifying' effects, although the utility of this distinction has been questioned [9]. In other words, current medications cannot cure AD but may help lessen or stabilize signs and symptoms of AD for a limited time. In spite of enormous research efforts, only a few symptomatic treatment options currently exist [10].

However, adequate dementia management requires a wide range of interventions to help maximize the patient's independence, increase his/her self-confidence and relieve the burden to the caregiver [11]. We are in desperate need of readily available safe interventions that modify disease course [12]. In the last decades, also several natural products have been tested for preventing the onset of dementia or delaying its progression [13]. Despite being widely used and tested, the efficacy of such natural medication in the prevention and treatment of dementia still remains controversial.

MLC601 is a traditional Chinese medicine that has shown both neuroprotective and neurodegenerative properties in several controlled studies of ischemic injury to the brain [14-21]. However, it has been shown that MLC601 is a possible modulator of amyloid precursor protein (APP) processing and has implications as a putative therapeutic strategy for the treatment of poststroke dementia and AD [22]. In a clinical trial study, MLC601 showed favorable tolerability and encouraging effectiveness on cognitive function in AD patients during 18 months of treatment when compared to rivastigmine [23].

In this study, we attempted to evaluate the effectiveness of MLC601 in the treatment of mild to moderate $\mathrm{AD}$ as compared to the 3 approved ChEIs donepezil, rivastigmine and galantamine. In addition, we aimed to determine the side effects in 4 study groups. For this reason, we monitored the cognitive changes and side effects during the 16-month follow-up.

\section{Materials and Methods}

\section{Participants}

Patients with mild to moderate AD who fulfilled our inclusion criteria were recruited for the study. The inclusion criteria were age $>60$ years, Mini-Mental State Examination (MMSE) scores ranging from 10 to 26, ability to sign an informed consent form and a possible diagnosis of AD. Diagnosis was made according to the criteria for AD of the American Psychiatric Association Diagnostic and Statistical Manual of Mental Disorders, ed 4 [24].

Brain magnetic resonance imaging was done to rule out significant central nervous system lesions. Ischemic dementia was excluded according to clinical and laboratory tests, brain imaging study, and a Hachinski Ischemic Scale [25] score <4. Exclusion criteria were: psychiatric or mental disorders, serious physical illness, other neurological diseases, hypo- 


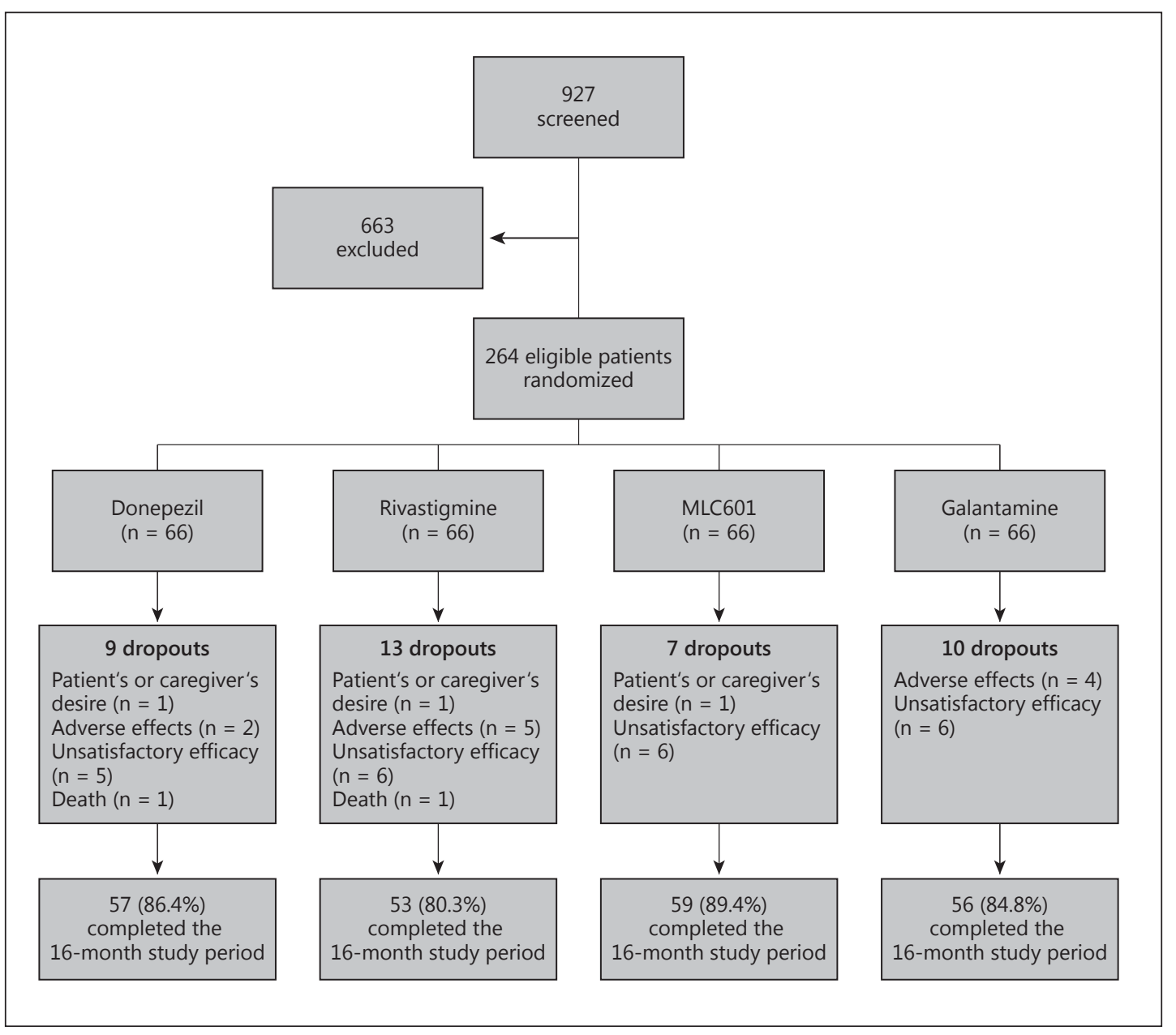

Fig. 1. The profile of the study.

thyroidism, diabetes mellitus, liver or renal disease, addiction, other causes of dementia than $\mathrm{AD}$, being already on ChEI treatment at study entry, participation in another treatment trial within the prior 16 months and contraindications to ChEIs.

\section{Study Design}

We designed our study as a multicenter, nonblinded, randomized controlled clinical trial to evaluate the effectiveness and safety of MLC601 in the treatment of mild to moderate AD as compared to the 3 approved ChEIs donepezil, rivastigmine and galantamine. A total of 927 patients with $\mathrm{AD}$ were screened, and after considering the inclusion and exclusion criteria, 264 eligible volunteers with AD were randomly divided into 4 groups of 66; groups 1, 2, 3 and 4 received donepezil, rivastigmine, MLC601 and galantamine, respectively. A sample size of 54 in each group was calculated to detect a 5-point score difference in effect size with a standard deviation of 8 for $5 \%$ precision and $90 \%$ power. It was increased to 66 subjects to enhance power. Simple randomization was performed using computer-generated random allocation sequence. The study protocol is shown as a flowchart in figure 1.

MLC601 (NeuroAid, Moleac Pte. Ltd, Singapore; $0.4 \mathrm{~g}$ per capsule) was prescribed as one capsule three times daily. MLC601 contains 5 animal components $(0.0665 \mathrm{~g}$ Hirudo, $0.0285 \mathrm{~g}$ Cornu saigae tataricae, $0.095 \mathrm{~g}$ Buthus martensii, $0.0665 \mathrm{~g}$ Eupolyphaga seu steleophaga and 
Pakdaman et al.: Effectiveness and Safety of MLC601 in the Treatment of Mild to

Moderate Alzheimer's Disease: A Multicenter, Randomized Controlled Trial

0.0285 g Calculus bovisartifactus) and 9 herbal components (0.114 g radix Paeoniae rubra, $0.57 \mathrm{~g}$ radix astragali, $0.114 \mathrm{~g}$ radix Salvia miltiorrhizae, $0.114 \mathrm{~g}$ Rhizoma chuanxiong, $0.114 \mathrm{~g}$ radix Angelicae sinensis, 0.114 g radix polygalae, 0.114 g Prunus persica, 0.114 g Carthamus tinctorius and $0.114 \mathrm{~g}$ Rhizoma acori tatarinowii). Patients in the other 3 groups received standard medication of ChEIs according to clinical response and recommended maximum or tolerable dose.

\section{Ethical Issues}

The study protocol was explained to each patient and his/her caregivers, and they provided written informed consent. The study was designed in accordance with the Helsinki Declaration and approved by the Ethics Committee at Shahid Beheshti University of Medical Sciences. The participants were allowed to discontinue the study at any time. Medications other than the mentioned antidementia ones were allowed to be taken.

\section{Outcome Measures}

At screening, all patients underwent a detailed medical history taking, physical and neurological examinations, clinical interview, and laboratory evaluations. Almost all clinical trials on the symptomatic therapy for AD use MMSE and/or the Alzheimer's Disease Assessment Scale - Cognitive subscale (ADAS-Cog) [26]. Therefore, all subjects underwent a clinical diagnostic interview and a cognitive/functional battery including MMSE and ADASCog. Patients were visited every 4 months, and the score of cognition was recorded by the neurologists.

\section{Alzheimer's Disease Assessment Scale - Cognitive Subscale}

ADAS-Cog was constructed by Rosen et al. [27] to measure the cognitive aspects of AD. The standard ADAS-Cog includes 11 items, of which 7 are short cognitive tests: Word recall, Naming (objects and fingers), (Following) Commands, Constructional praxis, Ideational praxis, Orientation and Word recognition, and 4 are scales rated by the clinician: Remembering test instructions, Spoken language ability, Word-finding difficulty and Comprehension [28]. The majority of studies with ADAS-Cog use the standard scale described above, which represents the most widely adopted cognitive outcome measure in AD trials. The score ranges from 0 to 70, with higher scores indicating greater cognitive impairment.

\section{Mini-Mental State Examination}

MMSE was used to measure the cognitive aspects of mental status [29]. It contains 10 items including Orientation, Registration, Attention, Recall, Language, Naming, Repetition, Comprehension, Reading ability, Writing ability and Visual construction. The MMSE scale ranges from 0 to 30 , and the higher the score the better the cognitive performance.

\section{Safety Measures}

Safety was evaluated monthly by recording adverse events reported by the participants and their study partner and vital signs. We also performed physical and neurological examinations, and laboratory tests including complete cell blood count, serum blood urea nitrogen, aspartate aminotransferase, alanine transaminase, creatinine, calcium, phosphorus, sodium, potassium, prothrombin time, partial thromboplastin time, and international normalized ratio.

\section{Statistical Analysis}

The SPSS software, version 16.0 (SPSS Inc., Chicago, Ill., USA), was used to perform the statistical analyses. The level of significance was set at $p<0.05$. The $\chi^{2}$ test and ANOVA were 
Table 1. Baseline characteristics of the subjects

\begin{tabular}{llllll}
\hline Variable & Donepezil & Rivastigmine & MLC601 & Galantamine & p value \\
\hline Total & 66 & 66 & 66 & 66 & - \\
Age, years & $71.8 \pm 5.5$ & $73.2 \pm 4.7$ & $71.8 \pm 5.7$ & $72.5 \pm 5.2$ & 0.375 \\
Female & $41(62.1 \%)$ & $35(53.0 \%)$ & $37(56.1 \%)$ & $37(56.1 \%)$ & 0.759 \\
Married & $55(83.3 \%)$ & $56(84.8 \%)$ & $58(87.9 \%)$ & $57(86.4 \%)$ & 0.893 \\
MMSE & $17.6 \pm 2.8$ & $17.1 \pm 3.1$ & $17.7 \pm 1.6$ & $17.9 \pm 1.9$ & 0.303 \\
ADAS-Cog & $27.8 \pm 6.5$ & $29.6 \pm 7.7$ & $27.5 \pm 4.1$ & $27.3 \pm 5.0$ & 0.100 \\
\hline
\end{tabular}

Table 2. Educational status in the 4 study groups

\begin{tabular}{lcccrr}
\hline Education & Donepezil & Rivastigmine & MLC601 & Galantamine & Total \\
\hline Illiterate & $6(9.1 \%)$ & $4(6.1 \%)$ & $2(3.0 \%)$ & $1(1.5 \%)$ & $13(4.9 \%)$ \\
Lettered & $8(12.1 \%)$ & $5(7.6 \%)$ & $6(9.1 \%)$ & $8(12.1 \%)$ & $27(10.2 \%)$ \\
Middle school & $7(10.6 \%)$ & $11(16.7 \%)$ & $13(19.7 \%)$ & $9(13.6 \%)$ & $40(15.2 \%)$ \\
Diploma & $32(48.5 \%)$ & $26(39.4 \%)$ & $31(47.0 \%)$ & $30(45.5 \%)$ & $119(45.1 \%)$ \\
College & $13(19.7 \%)$ & $20(30.3 \%)$ & $14(21.2 \%)$ & $18(27.3 \%)$ & $65(24.6 \%)$ \\
\hline
\end{tabular}

Table 3. Causes of dropout and dropout number

\begin{tabular}{lccccc}
\hline Causes of dropout & Donepezil & Rivastigmine & MLC601 & Galantamine & Total \\
\hline No exit & $57(86.4 \%)$ & $53(80.3 \%)$ & $59(89.4 \%)$ & $56(84.8 \%)$ & $225(85.2 \%)$ \\
Patient's or caregiver's desire & $1(1.5 \%)$ & $1(1.5 \%)$ & $1(1.5 \%)$ & 0 & $3(1.1 \%)$ \\
Adverse effects & $2(3.0 \%)$ & $5(7.6 \%)$ & 0 & $4(6.1 \%)$ & $11(4.1 \%)$ \\
Unsatisfactory efficacy & $5(7.6 \%)$ & $6(9.1 \%)$ & $6(9.1 \%)$ & $6(9.1 \%)$ & $23(8.7 \%)$ \\
Death & $1(1.5 \%)$ & $1(1.5 \%)$ & 0 & 0 & $2(0.7 \%)$ \\
\hline
\end{tabular}

used to analyze qualitative and quantitative variables, respectively. In order to compare changes over time for MMSE and ADAS-Cog scores between the 4 patient groups, repeated measures analysis was performed.

\section{Results}

The baseline characteristics of the 264 patients are shown in table 1 . There were no significant differences in age, sex, marital status and baseline score of cognition among the 4 groups. Educational status did not differ statistically among groups (PV = 0.59; table 2).

\section{Safety Profile}

Thirty-nine patients (14.7\%) left the study. Finally, 57 (86.4\%; 63.1\% female), 53 (80.3\%; $54.7 \%$ female), 59 (89.4\%; 54.2\% female) and 56 (84.8\%; 53.5\% female) patients in group 1, 2, 3 and 4, respectively, completed 16 months of follow-up. The dropout numbers were not different among groups. The reasons for dropout were investigated and included death, patient's or caregiver's desire, unsatisfactory efficacy and presence of severe side effects $(\mathrm{p}=$ 
Pakdaman et al.: Effectiveness and Safety of MLC601 in the Treatment of Mild to Moderate Alzheimer's Disease: A Multicenter, Randomized Controlled Trial

Table 4. Mean of side effects in the 4 study groups

\begin{tabular}{|c|c|c|c|c|c|c|}
\hline & \multirow[t]{2}{*}{ Number } & \multirow[t]{2}{*}{ Mean \pm SD } & \multicolumn{2}{|c|}{$95 \%$ confidence interval } & \multirow[t]{2}{*}{ Minimum } & \multirow[t]{2}{*}{ Maximum } \\
\hline & & & lower bound & upper bound & & \\
\hline Donepezil & 66 & $1.86 \pm 2.49$ & 1.24 & 2.48 & 0 & 9 \\
\hline Rivastigmine & 66 & $2.86 \pm 3.28$ & 2.05 & 3.67 & 0 & 10 \\
\hline MLC601 & 66 & $0.51 \pm 1.29$ & 0.19 & 0.83 & 0 & 6 \\
\hline Galantamine & 66 & $2.37 \pm 3.0$ & 1.64 & 3.11 & 0 & 10 \\
\hline Total & 263 & $1.90 \pm 2.76$ & 0.17 & 1.56 & 2.24 & 10 \\
\hline
\end{tabular}

Table 5. Frequency distribution of side effects in the 4 study groups

\begin{tabular}{|c|c|c|c|c|c|}
\hline Side effect & Donepezil & Rivastigmine & MLC601 & Galantamine & $\mathrm{p}$ value \\
\hline Nausea & $14(21.2 \%)$ & $15(22.7 \%)$ & $6(9.1 \%)$ & $21(31.8 \%)$ & $0.01^{*}$ \\
\hline Vomiting & $4(6.1 \%)$ & $8(12.1 \%)$ & $1(1.5 \%)$ & $10(15.2 \%)$ & $0.02^{*}$ \\
\hline Diarrhea & $5(7.6 \%)$ & $9(13.6 \%)$ & $3(4.5 \%)$ & $5(7.6 \%)$ & 0.28 \\
\hline Anorexia & $15(23.1 \%)$ & $11(16.7 \%)$ & $4(6.1 \%)$ & $17(25.8 \%)$ & $0.01^{*}$ \\
\hline Weight loss & $4(6.1 \%)$ & $7(10.6 \%)$ & $1(1.5 \%)$ & $3(4.5 \%)$ & 0.15 \\
\hline Abdominal discomfort & $3(4.5 \%)$ & $7(10.6 \%)$ & 0 & $9(13.6 \%)$ & $0.01^{*}$ \\
\hline Tenesmus & $4(6.1 \%)$ & $14(21.2 \%)$ & $4(6.1 \%)$ & $4(6.1 \%)$ & $0.005^{*}$ \\
\hline Abdominal pain & $8(12.1 \%)$ & $9(13.6 \%)$ & $4(6.1 \%)$ & $10(15.2 \%)$ & 0.38 \\
\hline No cardiac chest pain & $8(12.1 \%)$ & $7(10.6 \%)$ & $3(4.5 \%)$ & $13(19.7 \%)$ & 0.06 \\
\hline Fatigue & $2(3.0 \%)$ & $9(13.6 \%)$ & $3(4.5 \%)$ & $5(7.6 \%)$ & 0.08 \\
\hline Sialorrhea & 0 & $1(1.5 \%)$ & 0 & $4(6.1 \%)$ & $0.03^{*}$ \\
\hline Constipation & $9(13.6 \%)$ & $10(15.2 \%)$ & 0 & $6(9.1 \%)$ & $0.01^{*}$ \\
\hline Hyperhidrosis & $3(4.5 \%)$ & $3(4.5 \%)$ & 0 & $2(3.0 \%)$ & 0.37 \\
\hline Gastrointestinal bleeding & 0 & $1(1.5 \%)$ & 0 & $2(3.0 \%)$ & 0.29 \\
\hline Cardiac arrhythmia & 0 & $1(1.5 \%)$ & 0 & 0 & 0.39 \\
\hline Palpitation & $5(7.6 \%)$ & $4(6.1 \%)$ & $1(1.5 \%)$ & $5(7.6 \%)$ & 0.38 \\
\hline Light-headedness & $2(3.0 \%)$ & $8(12.1 \%)$ & $2(3.0 \%)$ & $4(6.1 \%)$ & 0.09 \\
\hline Hallucination & $3(4.5 \%)$ & $3(4.5 \%)$ & 0 & $1(1.5 \%)$ & 0.26 \\
\hline Drowsiness & $1(1.5 \%)$ & $5(7.6 \%)$ & 0 & 0 & $0.009^{*}$ \\
\hline Depression & $2(3.0 \%)$ & $5(7.6 \%)$ & 0 & $2(3.0 \%)$ & 0.11 \\
\hline Dizziness & $4(6.1 \%)$ & $15(22.7 \%)$ & $1(1.5 \%)$ & $8(12.1 \%)$ & $0.001 *$ \\
\hline Headache & $9(13.6 \%)$ & $14(21.2 \%)$ & $1(1.5 \%)$ & $13(19.7 \%)$ & $0.004^{*}$ \\
\hline Insomnia & $11(16.7 \%)$ & $16(24.2 \%)$ & 0 & $8(12.1 \%)$ & $<0.0001^{*}$ \\
\hline Confusion & $5(7.6 \%)$ & $7(10.6 \%)$ & 0 & $5(7.6 \%)$ & 0.08 \\
\hline
\end{tabular}

$* \mathrm{p}<0.05$, statistically significant.

0.52). The two most common causes of dropout were unsatisfactory efficacy (8.7\%) and adverse effects (4.1\%). The causes of dropout and dropout numbers are shown in table 3 . Two deaths due to pneumonia were registered in the donepezil and rivastigmine groups.

The mean number of side effects was statistically significant among groups $(\mathrm{p}<0.0001)$ with the least events in the MLC601 group (table 4). Frequency distribution of side effects is presented in table 5 .

\section{Efficacy Profile}

The mean MMSE scores and the mean changes from baseline at the different visits are shown in table 6 . The mean change in MMSE over 16 months for the donepezil group was 
Pakdaman et al.: Effectiveness and Safety of MLC601 in the Treatment of Mild to Moderate Alzheimer's Disease: A Multicenter, Randomized Controlled Trial

Table 6. Means and standard deviations of MMSE scores in each group

\begin{tabular}{llllll}
\hline Group & Baseline & 4th month & 8th month & 12th month & 16th month \\
\hline Donepezil & $17.66(2.86)$ & $17.69(3.92)$ & $18.00(3.70)$ & $17.56(3.70)$ & $17.36(3.71)$ \\
Rivastigmine & $17.13(3.15)$ & $16.86(3.95)$ & $17.19(3.94)$ & $17.46(3.45)$ & $17.24(3.43)$ \\
MLC601 & $17.77(1.69)$ & $18.15(2.65)$ & $18.25(2.50)$ & $17.90(2.33)$ & $17.47(2.21)$ \\
Galantamine & $17.90(1.92)$ & $18.09(2.87)$ & $17.88(3.13)$ & $17.56(3.02)$ & $17.30(3.09)$ \\
\hline
\end{tabular}

Table 7. Means and standard deviations of ADAS-Cog scores in each group

\begin{tabular}{llllll}
\hline Group & Baseline & 4th month & 8th month & 12th month & 16th month \\
\hline Donepezil & $27.80(6.56)$ & $28.10(8.58)$ & $27.48(7.67)$ & $28.27(7.87)$ & $28.87(7.67)$ \\
Rivastigmine & $29.69(7.78)$ & $30.12(9.39)$ & $29.42(9.30)$ & $28.62(7.91)$ & $29.37(7.63)$ \\
MLC601 & $27.51(4.19)$ & $27.06(6.52)$ & $26.75(5.96)$ & $27.55(6.15)$ & $28.45(6.04)$ \\
Galantamine & $27.37(5.02)$ & $26.98(6.45)$ & $27.60(7.48)$ & $28.40(7.36)$ & $29.14(7.65)$ \\
\hline
\end{tabular}

-0.50 points $( \pm 3.5)$, for the rivastigmine group it was -0.56 points $( \pm 2.9)$, for the MLC601 group -0.45 points $( \pm 1.9)$ and for the galantamine group -0.43 points $( \pm 2.6)$.

The mean ADAS-Cog scores and the mean changes from baseline at the different visits are shown in table 7. The mean change in ADAS-Cog during 16 months for the donepezil group was 1.6 points $( \pm 7.6)$, for the rivastigmine group it was 1.6 points ( \pm 6.7$)$, for the MLC601 group 1.35 points $( \pm 5.3)$ and for the galantamine group 1.2 points $( \pm 6.1)$.

The mean differences of both MMSE and ADAS-Cog generally increased during the first 8 months. The trend of cognition changes based on the modifications over time of the MMSE (fig. 2) and ADAS-cog scores (fig. 3) did not differ significantly among groups ( $p=0.92$ for MMSE and $p=0.87$ for ADAS-Cog).

\section{Discussion}

Current medications cannot cure AD but may help lessen or stabilize symptoms of AD for a limited time. There are five prescription drugs approved by the US Food and Drug Administration (FDA) - donepezil, galantamine, rivastigmine, tacrine and memantine - to treat its symptoms. The first 4 drugs are ChEIs, which can prevent the breakdown of acetylcholine involved in memory, judgment and other thought progress. However, these drugs have common side effects including nausea, vomiting, loss of appetite and increased frequency of bowel movements [30]. Additional evidence suggests that the response to ChEIs may be quite variable, with as many as $30-50 \%$ of patients showing no observable benefit [31,32], while a smaller proportion (up to 20\%) may show a greater than average response ( $\geq 7$-point ADAS-Cog improvement) [33, 34]. In their systematic review, Raina et al. [35] concluded that treatment of dementia with ChEIs and memantine can result in a statistically significant but clinically marginal improvement in measures of cognition and global assessment of dementia.

Despite controversies, ChEIs have been promoted during the last 15 years as symptomatic treatment of mild to moderate AD. Several meta-analyses have reported a modest effect of ChEIs on cognition [35-37]. The exponential rise in the prevalence, incidence and 
Pakdaman et al.: Effectiveness and Safety of MLC601 in the Treatment of Mild to Moderate Alzheimer's Disease: A Multicenter, Randomized Controlled Trial

Fig. 2. Mean changes in MMSE score from baseline in the 4 groups of patients with AD.

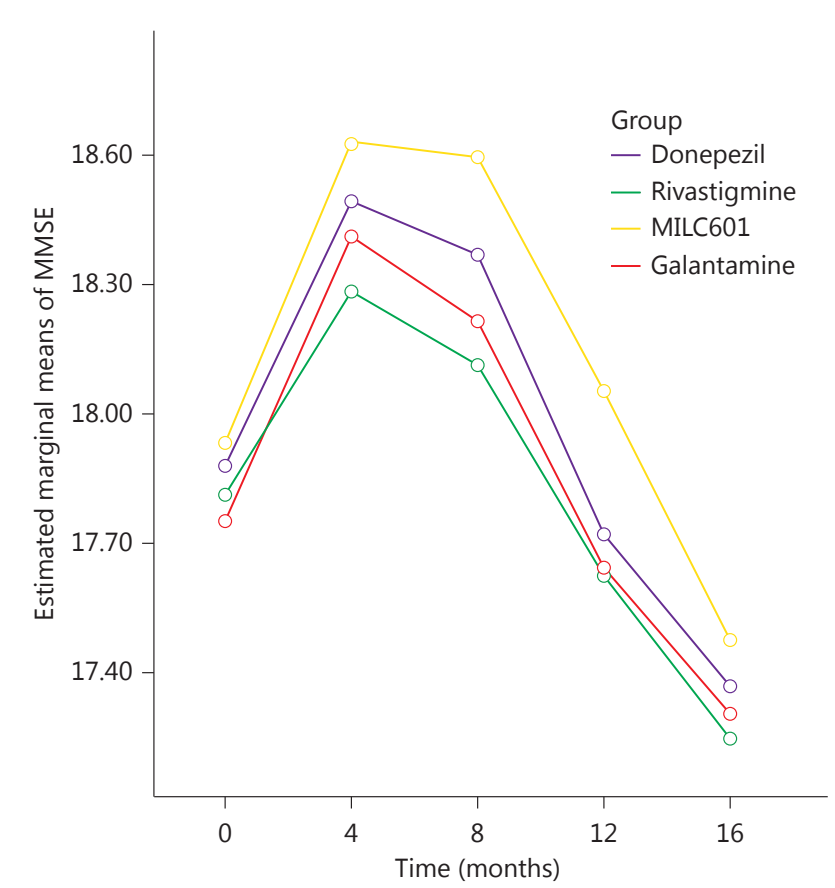

Fig. 3. Mean changes in ADAS-Cog score from baseline in the 4 groups of patients with $\mathrm{AD}$.

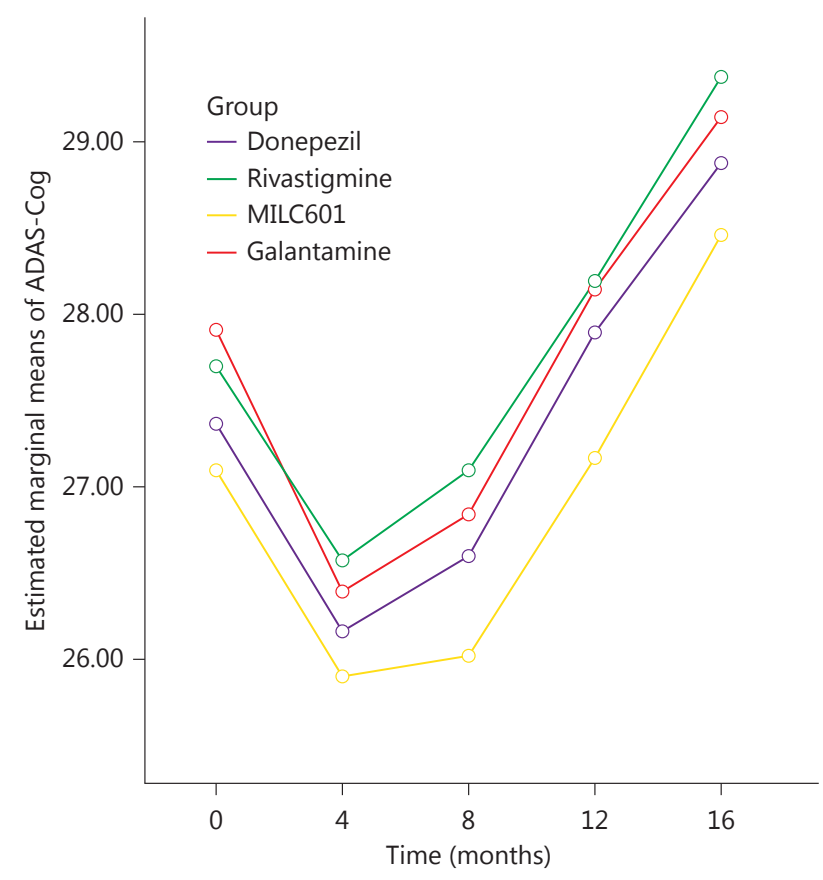


cost of care for $\mathrm{AD}$ make finding therapeutic agents that can delay disease progression an urgent public health concern [38]. Therefore, promising new treatments to slow or stop the progress of $\mathrm{AD}$ are urgently needed [39]. The response to ChEIs varies within the AD population. Multiple factors have been outlined that enhance the response to ChEI treatment in AD [40]; however, there are no standard guidelines that define the response to treatment. The choice between ChEIs is largely based upon cost, individual patient tolerability and physician experience as their efficacy appears to be similar [35, 37, 41].

In a previous study, 124 patients with mild to moderate $\mathrm{AD}$ who had previously failed to tolerate or benefit from treatment with rivastigmine were switched to an MLC601 regimen. Two patients were lost to follow-up and 122 completed the 18-month trial. Improved cognitive function was observed in the first 6 months of the regimen (ADAS-Cog $=-3.1 \pm 10.1$; MMSE $=$ $1.2 \pm 3.0$ ), and stabilization of cognitive decline was observed over the remaining 12 months (ADAS-Cog $=-1.6 \pm 7.6$; MMSE $=0.8 \pm 4.2$ ). Adverse effects were predominantly gastrointestinal and occurred in $7.3 \%$ of patients [23]. In the current study, the mean change in MMSE and ADAS-Cog over 16 months for the MLC601 group was -0.45 and 1.35 points $( \pm 5.3)$, respectively. Cognition scores improved in the first 8 months and then declined slightly up to the 16th month in all 4 groups. Side effects were significantly lower in the MLC601 group compared to the other groups. In the 3 approved treatment groups, donepezil showed the lowest mean number of side effects (1.86), which was 3.6 times more than MLC601, and rivastigmine had the highest number of side effects, i.e. 5.6 times more than MLC601. Accordingly, MLC601 dramatically showed minimum adverse events among the 4 groups $(1.86: 0.51=3.6$, and rivastigmine $2.81: 0.51=5.6$; table 2$)$. Tolerability is very important in patients with $\mathrm{AD}$ since the therapeutic effect is often compromised by the occurrence of adverse events and discontinuation of treatment [42].

Most studies on ChEIs were of short duration, i.e. 6 months, which limited their ability to detect a delay in the onset or progression of dementia [35]. Low completion rates are another difficulty of long-term studies of AD patients, both with or without treatment. Three-year completion rates range between 4 and 39\% [43-45], making it difficult to fully comprehend the long-term outcomes of treatment in AD [46]. Because ethical constraints prohibit the use of long-term, placebo-controlled studies of ChEIs in AD, the analysis of results from open-label, long-term trials is important. In this study, we monitored the longterm efficacy of MLC601 during the extended follow-up duration over 16 months [26]. Such an adequate follow-up in our study is a notable evidence for monitoring the trend of changes in patients who are on 3 types of ChEIs. In addition, the withdrawal rate was low in this study, and only $14.7 \%$ of subjects left the study. This point is another advantage of the study.

There is convergent evidence that overproduction, aberrant aggregation, and decreased elimination of different forms of amyloid beta protein are critical events in the pathogenesis of $\mathrm{AD}$ and, therefore, treatment development has focused on these processes [12]. In AD, APP is preferentially processed via the amyloidogenic pathway, producing large amounts of amyloid beta protein that forms the major constituent of senile plaques and tau-containing neurofibrillary tangles [22]. Since MLC601 has some neuroprotective effects, it is possible that it may exert its neuroprotective effects via the regulation of APP processing. MLC601 is a possible modulator of APP processing. Lim et al. [22] found that MLC601 induced a decrease in APP and enhanced the secreted forms of APP $\alpha$ release, suggesting that MLC601 may act by promoting the processing of APP via the nonamyloidogenic pathway.

We did not specifically measure our patients' quality of life, activities of daily living, global outcome and behavior, which should be considered as study limitations. Neither the patients nor neurologists were blinded to medication. 
Pakdaman et al.: Effectiveness and Safety of MLC601 in the Treatment of Mild to Moderate Alzheimer's Disease: A Multicenter, Randomized Controlled Trial

\section{Conclusion}

MLC601 has shown a promising safety profile and also efficacy compared to the 3 FDAapproved ChEIs donepezil, rivastigmine and galantamine. There is a need to conduct more randomized controlled trials with a combination of MLC601 and ChEIs to find out whether MLC601 may provide additional cognitive and/or functional benefits in AD when combined with 'first-line' treatments.

\section{Disclosure Statement}

The authors declare that they have no competing interests.

\section{References}

1 Hippius H, Neundörfer G: The discovery of Alzheimer's disease. Dialogues Clin Neurosci 2003;5:101-108.

-2 Reitz C, Brayne C, Mayeux R: Epidemiology of Alzheimer disease. Nat Rev Neurol 2011;7:137-152.

-3 Ferri CP, Prince M, Brayne C, Brodaty H, Fratiglioni L, Ganguli M, Hall K, Hasegawa K, Hendrie H, Huang Y, Jorm A, Mathers C, Menezes PR, Rimmer E, Scazufca M; Alzheimer's Disease International: Global prevalence of dementia: a Delphi consensus study. Lancet 2005;366:2112-2117.

4 Cummings JL, Cole G: Alzheimer disease. JAMA 2002;287:2335-2338.

5 Rogers SL, Friedhoff LT: The efficacy and safety of donepezil in patients with Alzheimer's disease: results of a US multicentre, randomized, double-blind, placebo-controlled trial. The Donepezil Study Group. Dementia 1996;7: 293-303.

-6 Rösler M, Anand R, Cicin-Sain A, Gauthier S, Agid Y, Dal-Bianco P, Stähelin HB, Hartman R, Gharabawi M: Efficacy and safety of rivastigmine in patients with Alzheimer's disease: international randomised controlled trial. BMJ 1999;318:633-638.

7 Raskind MA, Peskind ER, Wessel T, Yuan W: Galantamine in AD: a 6-month randomized, placebo-controlled trial with a 6-month extension. The Galantamine USA-1 Study Group. Neurology 2000;54:2261-2268.

-8 Tariot PN, Farlow MR, Grossberg GT, Graham SM, McDonald S, Gergel I; Memantine Study Group: Memantine treatment in patients with moderate to severe Alzheimer disease already receiving donepezil: a randomized controlled trial. JAMA 2004;291:317-324.

-9 Doody RS: We should not distinguish between symptomatic and disease-modifying treatments in Alzheimer's disease drug development. Alzheimers Dement 2008;4(suppl 1):S21-S25.

$\$ 10$ Heo JH, Lee ST, Oh MJ, Park HJ, Shim JY, Chu K, Kim M: Improvement of cognitive deficit in Alzheimer's disease patients by long term treatment with Korean red ginseng. J Ginseng Res 2011;35:457-461.

11 Tárraga L, Boada M, Modinos G, Espinosa A, Diego S, Morera A, Guitart M, Balcells J, López OL, Becker JT: A randomised pilot study to assess the efficacy of an interactive, multimedia tool of cognitive stimulation in Alzheimer's disease. J Neurol Neurosurg Psychiatry 2006;77:1116-1121.

-12 Ringman JM, Frautschy SA, Teng E, Begum AN, Bardens J, Beigi M, Gylys KH, Badmaev V, Heath DD, Apostolova LG, Porter V, Vanek Z, Marshall GA, Hellemann G, Sugar C, Masterman DL, Montine TJ, Cummings JL, Cole GM: Oral curcumin for Alzheimer's disease: tolerability and efficacy in a 24-week randomized, double blind, placebocontrolled study. Alzheimers Res Ther 2012;4:43.

13 Canevelli M, Adali N, Kelaiditi E, Cantet C, Ousset PJ, Cesari M; ICTUS/DSA Group: Effects of Gingko biloba supplementation in Alzheimer's disease patients receiving cholinesterase inhibitors: data from the ICTUS study. Phytomedicine 2014;21:888-892.

14 Quintard H, Lorivel T, Gandin C, Lazdunski M, Heurteaux C: MLC901, a traditional Chinese medicine induces neuroprotective and neuroregenerative benefits after traumatic brain injury in rats. Neuroscience 2014;277: 72-86.

15 Chen CL, Young SH, Gan HH, Singh R, Lao AY, Baroque AC 2nd, Chang HM, Hiyadan JH, Chua CL, Advincula JM, Muengtaweepongsa S, Chan BP, de Silva HA, Towanabut S, Suwanwela NC, Poungvarin N, Chankrachang S, Wong KS, Eow GB, Navarro JC, Venketasubramanian N, Lee CF, Bousser MG; CHIMES Study Investigators: Chinese medicine neuroaid efficacy on stroke recovery: a double-blind, placebo-controlled, randomized study. Stroke 2013;44:2093-2100.

16 Siddiqui FJ, Venketasubramanian N, Chan ES, Chen C: Efficacy and safety ofMLC601 (NeuroAiD ${ }^{\circledR}$ ), a traditional Chinese medicine, in poststroke recovery: a systematic review. Cerebrovasc Dis 2013;35(suppl 1):8-17.

17 Navarro JC, Molina MC, Baroque Ii AC, Lokin JK: The use of NeuroAiD (MLC601) in postischemic stroke patients. Rehabil Res Pract 2012;2012:506387.

18 Quintard H, Borsotto M, Veyssiere J, Gandin C, Labbal F, Widmann C, Lazdunski M, Heurteaux C: MLC901, a traditional Chinese medicine protects the brain against global ischemia. Neuropharmacology 2011;61:622-631. 
Pakdaman et al.: Effectiveness and Safety of MLC601 in the Treatment of Mild to

Moderate Alzheimer's Disease: A Multicenter, Randomized Controlled Trial

19 Heurteaux C, Gandin C, Borsotto M, Widmann C, Brau F, Lhuillier M, Onteniente B, Lazdunski M: Neuroprotective and neuroproliferative activities of NeuroAid (MLC601, MLC901), a Chinese medicine, in vitro and in vivo. Neuropharmacology 2010;58:987-1001.

20 Venketasubramanian N, Young S, Tay SS, Chang HM, Umapathi T, Chan B, de Silva A, Wong L, Navarro J, Zhao YD, Tan SB, Chen C: Chinese medicine NeuroAiD efficacy stroke recovery-extension study (CHIMES-E study): an observational multicentre study to investigate the longer-term efficacy of NeuroAiD in stroke recovery. Cerebrovasc Dis 2013;35(suppl 1):18-22.

21 Young SH, Zhao Y, Koh A, Singh R, Chan BP, Chang HM, Venketasubramanian N, Chen C; CHIMES Investigators: Safety profile of MLC601 (NeuroAiD) in acute ischemic stroke patients: a Singaporean substudy of the Chinese medicine neuroAiD efficacy on stroke recovery study. Cerebrovasc Dis 2010;30:1-6.

$\checkmark 22$ Lim YA, Murray LA, Lai MK, Chen C: NeuroAiD ${ }^{\circledR}$ (MLC601) and amyloid precursor protein processing. Cerebrovasc Dis 2013;35(suppl 1):30-37.

23 Harandi AA, Ashrafi F, Tabatabaei M, Ghorbani A, Hatamian HR, Pakdaman H, Ilkhani M, Gharagozli K, et al: Efficacy and tolerability of MlC601 in patients with mild to moderate Alzheimer disease who were unable to tolerate or failed to benefit from treatment with rivastigmine. Br J Med Med Res 2013;3:341-350.

24 American Psychiatric Association: Diagnostic and Statistical Manual of Mental Disorders-Fourth Edition (DSMIV). Washington, American Psychiatric Press, 1994, pp 147-154.

25 Hachinski VC, Lassen NA, Marshall J: Multi-infarct dementia: a cause of mental deterioration in the elderly. Lancet 1974;2:207-209.

26 Persson CM, Wallin AK, Levander S, Minthon L: Changes in cognitive domains during three years in patients with Alzheimer's disease treated with donepezil. BMC Neurol 2009;9:7.

Rosen WG, Mohs RC, Davis KL: A new rating scale for Alzheimer's disease. Am J Psychiatry 1984;141:1356-1364. Weyer G, Erzigkeit H, Kanowski S, Ihl R, Hadler D: Alzheimer's Disease Assessment Scale: reliability and validity in a multicenter clinical trial. Int Psychogeriatr 1997;9:123-138.

29 Folstein MF, Folstein SE, McHugh PR: 'Mini-mental state'. A practical method for grading the cognitive state of patients for the clinician. J Psychiatr Res 1975;12:189-198.

30 Alzheimer's Association: FDA-Approved Treatment for Alzheimer's. http://www.alz.org (accessed January 29, 2013).

-31 Cummings JL: Use of cholinesterase inhibitors in clinical practice: evidence-based recommendations. Am J Geriatr Psychiatry 2003;11:131-145.

32 Clark CM, Karlawish JH: Alzheimer disease: current concepts and emerging diagnostic and therapeutic strategies. Ann Intern Med 2003;138:400-410.

33 Langa KM, Foster NL, Larson EB: Mixed dementia: emerging concepts and therapeutic implications. JAMA 2004; 292:2901-2908.

Grossberg GT, Desai AK: Management of Alzheimer’s disease. J Gerontol A Biol Sci Med Sci 2003;58:331-353. , Santaguida P, Ismaila A, Patterson C, Cowan D, Levine M, Booker L, Oremus M: Effectiveness of cholinesterase inhibitors and memantine for treating dementia: evidence review for a clinical practice guideline. Ann Intern Med 2008;148:379-397.

-36 Birks JS, Melzer D, Beppu H: Donepezil for mild and moderate Alzheimer's disease. Cochrane Database Syst Rev 2000;CD001190.

-37 Trinh NH, Hoblyn J, Mohanty S, Yaffe K: Efficacy of cholinesterase inhibitors in the treatment of neuropsychiatric symptoms and functional impairment in Alzheimer disease: a meta-analysis. JAMA 2003;289:210-216.

-38 Shinto L, Quinn J, Montine T, Dodge HH, Woodward W, Baldauf-Wagner S, Waichunas D, Bumgarner L, Bourdette D, Silbert L, Kaye J: A randomized placebo-controlled pilot trial of omega-3 fatty acids and alpha lipoic acid in Alzheimer's disease. J Alzheimers Dis 2014;38:111-120.

39 Yang G, Wang Y, Tian J, Liu JP: Huperzine A for Alzheimer's disease: a systematic review and meta-analysis of randomized clinical trials. PLoS One 2013;8:e74916.

-40 Lanctôt KL, Herrmann N, LouLou MM: Correlates of response to acetylcholinesterase inhibitor therapy in Alzheimer's disease. J Psychiatry Neurosci 2003;28:13-26.

-41 Qaseem A, Snow V, Cross JT Jr, Forciea MA, Hopkins R Jr, Shekelle P, Adelman A, Mehr D, Schellhase K, CamposOutcalt D, Santaguida P, Owens DK; American College of Physicians/American Academy of Family Physicians Panel on Dementia: Current pharmacologic treatment of dementia: a clinical practice guideline from the American College of Physicians and the American Academy of Family Physicians. Ann Intern Med 2008;148:370-378.

-42 Lanctôt KL, Herrmann N, Yau KK, Khan LR, Liu BA, LouLou MM, et al: Efficacy and safety of cholinesterase inhibitors in Alzheimer's disease: a meta-analysis. CMAJ 2003;169:557-564.

43 Lyle S, Grizzell M, Willmott S, Benbow S, Clark M, Jolley D: Treatment of a whole population sample of Alzheimer's disease with donepezil over a 4-year period: lessons learned. Dement Geriatr Cogn Disord 2008;25:226-231.

-44 Wallin AK, Gustafson L, Sjögren M, Wattmo C, Minthon L: Five-year outcome of cholinergic treatment of Alzheimer's disease: early response predicts prolonged time until nursing home placement, but does not alter life expectancy. Dement Geriatr Cogn Disord 2004;18:197-206.

45 Winblad B, Wimo A, Engedal K, Soininen H, Verhey F, Waldemar G, Wetterholm AL, Haglund A, Zhang R, Schindler R: 3-year study of donepezil therapy in Alzheimer's disease: effects of early and continuous therapy. Dement Geriatr Cogn Disord 2006;21:353-363.

46 Wallin AK, Wattmo C, Minthon L: Galantamine treatment in Alzheimer's disease: response and long-term outcome in a routine clinical setting. Neuropsychiatr Dis Treat 2011;7:565-576. 